\title{
Recycling in Multi-Family Dwellings: Increasing Participation and Decreasing Contamination
}

\author{
Raymond De Young \\ Sally Boerschig \\ Sarah Carney \\ Anne Dillenbeck \\ Mark Elster \\ Susan Horst \\ Brad Kleiner \\ Bruce Thomson \\ University of Michigan
}

This study explored the promotion of recycling in multi-family dwellings. An exper-
imental design investigated four behavior change techniques: biweekly postcards
giving specific feedback to each dwelling unit as to quantity and contamination of
the recyclables, newsletters giving general information on recycling and the
amount recycled by the city as a whole, written pledges committing households to
recycle for a specified period, and volunteer coordinators who distributed informa-
tion and answered questions from residents. The effectiveness of these techniques
was compared against that of a control group. The findings suggest that volunteer
coordinators are not an effective intervention technique in multi-family dwellings,
and that feedback and commitment techniques are useful mainly for managing
contamination in medium sized complexes. The data also suggest that the size of a
multi-family dwelling complex significantly affects the amount of recyclables col-
lected and the level of contamination. Smaller complexes with less than ten units
recycled up to three times the amount on a per unit basis as complexes with more

Please address correspondence to Dr. De Young, School of Natural Resources and Environment, The University of Michigan, 430 East University Avenue, Ann Arbor, MI 48109-1115.

Population and Environment: A Journal of Interdisciplinary Studies

Volume 16, Number 3, January 1995

C 1995 Human Sciences Press, Inc. 
POPULATION AND ENVIRONMENT

units. Smaller units also had fewer problems with contamination in their recyclables. Several explanations are offered for the poor participation and performance in larger complexes.

It is estimated the United States generated 180 million tons of municipal solid waste in 1988 , equivalent to 4.0 pounds per person per day. A $10 \%$ increase in this value is projected for the year 2000 based on both population growth and an increase in the per capita waste generation rate (U.S. EPA, 1990). Precious nonrenewable resources are being lost in the waste stream. Yet despite its endorsement by large numbers of people, recycling is still not a commonplace behavior in the United States. Where programs do exist, they are generally focused on weekly or monthly curbside pick-up programs for single family residences. The provision of convenient recycling opportunities to multi-family dwellings is a relatively recent and rare development. This is true despite the fact that $27 \%$ of Americans live in apartments (Wood, 1991).

As multi-family dwelling recycling programs are just now starting up around the country, little is known about what will make these programs successful. Educational and promotional strategies for multi-family dwelling programs are often adaptations of strategies used in single-family residence programs. This is despite the fact that there are significant differences between the two types of living environments and possible differences in demographic characteristics of the residents. A number of constraints exist which make the operation of multi-family dwelling programs more problematic than single-family residence programs. Some logistical difficulties include: the lack of space in and around apartments to store recyclables; the lifestyle of apartment dwellers, who tend to be single, young, and mobile; the high turnover rate of tenants; and the unwillingness of owners and managers to bother with recycling (Benton and Fox, 1990). Low participation rates and contamination of the common collection site are frequently cited as problems (Magnuson, 1990). In a multifamily dwelling program where users share curbcarts (large $100^{+}$gallon containers), there is often no direct link between the people depositing and collecting the materials.

The purpose of this study was to investigate possible informational techniques or combinations of techniques that would most successfully increase recycling rates and decrease contamination in a multi-family dwelling recycling program. 
RAYMOND DEYOUNG ET AL.

\section{RESEARCH BACKGROUND}

Little is known about the differences between multi-family and singlefamily dwelling situations which might influence recycling behavior, as most of the research on the psychology of recycling behavior has been conducted on recyclers in single family residences. In particular, the increased scale and density of multi-family dwelling situations may affect the conservation behavior of the residents.

\section{Housing Complex Size}

Multi-family complex size may be a factor influencing recycling behavior due to the presence or absence of a sense of community, which influences the degree to which an individual feels needed or involved in a socially desirable behavior. Increased size and density of a residence and the area surrounding it have been shown to create feelings of anonymity and isolation among occupants. Freedman (1975) felt that high density may serve to intensify the effects of social isolation and anonymity. Zimbardo (1969) suggested that anonymity encouraged vandalism of public and private property and led to a unique set of norms controlling behavior in public places. Such settings may cause individuals to miss out on participation in social networks which can help foster individual identity and responsiveness to group norms. Sherrod and Cohen (1976) described high density environments as uncontrollable. These settings may lack the "sense of community" which is critical for human beings living together (Denman, 1970). In a large, heterogeneous situation, an individual can be subjected to deindividuation (Sadalla, 1978), which is characterized by lessened awareness of the self and decreased concern about the evaluations of others. In short, individual behavior and the environment can be viewed in terms of a set of interlocking relationships where social systems are influenced by the physical nature of the built environment (Davis, 1978). Hence, in multi-family dwellings, low rates of participation in recycling programs may be caused, in part, by norms of non-involvement and anonymity brought about by the scale of the setting. The relationship between the size of a community and the level of personal involvement has also been documented in educational settings. Individuals at smaller schools felt a sense of community and were more satisfied and involved when compared to individuals at larger schools (Barker \& Gump, 1964). Individuals in smaller scaled schools lived under greater day-to-day attraction, obligation, and external pressure to take part in the various behavior set- 
tings of the school than students in large schools. They also report more feelings of personal responsibility. This scale effect may play itself out in small multi-family housing complexes as an increased social pressure to recycle.

\section{Intervention Techniques}

Four different intervention techniques were employed to increase the quantity and quality of recycling: volunteer coordinators, written commitment in the form of a pledge, specific feedback in the form of a postcard and general feedback in the form of a newsletter. In general, each has been found to be effective at increasing conservation behavior (De Young, 1993). The literature supporting each is reviewed below.

Volunteer coordinators have been viewed as playing three important roles in recycling programs: 1) setting a norm or modeling desired social behavior; 2) acting as a prompt or reminder to recycle; and, 3) serving as a source of information on correct recycling techniques. In studies conducted for single family dwellings, volunteer coordinators have proven to be successful (Burn, 1991; Hopper \& Nielsen, 1991; Cook \& Berrenberg, 1981).

Commitment, in the form of a pledge, has been shown to be an effective means of eliciting recycling behavior (Burn \& Oskamp, 1986; Geller, 1989; Katzev \& Pardini, 1987-1988; Pardini \& Katzev, 1983-1984; Wang \& Katzev, 1990). The theory behind commitment is that it has the potential to elicit personal reasons to participate, which may include intrinsic motivation, which, in turn, is more likely to cause the desired behavior to continue after the commitment period is over. Prior research has suggested that written commitment is generally more successful than verbal commitment.

Specific and general feedback both provide evidence of, and information about, the utility and effectiveness of a behavior. Cook and Berrenberg (1981) view feedback as providing rewards for actions and motivation for the individual. Feedback also provides information on one's progress, particularly when the conservation behavior involves negative costs (Seligman, et al., 1981). Specific feedback gives an individual information on his or her personal behavior and how it may relate to the behavior of other individuals. General feedback gives an individual information on the behavior of the social aggregation that he or she belongs to. Social learning theory (Zimbardo \& Ebbesen, 1969) sees most behavior as leading to consequences which feed back to behavior; this theory posits that if the consequences are positive the behavior will recur. Making the consequences of 
RAYMOND DEYOUNG ET AL.

their actions salient to recyclers by direct feedback may thus result in a continuation of the behavior.

\section{METHODS}

\section{Research Setting and Design}

This study involved participants in a new recycling program for multifamily dwellings in the City of Ann Arbor, Michigan. The city first began recycling with a central drop-off site in 1970 and currently provides weekly curbside pick-up for all single-family dwellings. The program for multi-family dwellings, "Opportunity to Recycle", was initiated in April 1991. Tenant participation in the program is voluntary, but landlords are mandated to provide the opportunity to recycle. Individual multi-family buildings signed up and were brought into the program monthly from August 1991 to April 1992. In the program, pairs of 105 gallon curbcarts are provided for each 25 dwelling units and located outside the buildings near the garbage dumpsters. One curbcart holds newspaper and cardboard and the other holds commingled containers, including glass, plastic (e.g., milk jugs, plastic laundry bottles), aluminum and steel cans. Each resident was also provided with two buckets or "totes" (approximately 5 gallons each), one labeled for newspaper and the other for containers. These were for use within the dwellings and were designed for easy storing and movement in the confined quarters of multi-family structures.

The study utilized the $2 \times 3$ experimental design shown in Figure 1 . Multi-family complexes that signed up for the opportunity to recycle in September and October of 1991 (the second and third month of sign-up) had their curbcarts randomly assigned into the eight cells representing the different combinations of strategies to be investigated. All participants, including the control, received the baseline educational material sent to all multi-family dwellings involved in the city's program. This material included procedural information provided with the totes, graphically displayed procedural information inside the curbcarts, a promotional brochure in the mail (or from their volunteer coordinator), and the City's semi-annual newsletter on recycling called The Waste Watcher.

The volunteer coordinator program used in this study was a modified version of that used in the city's single-family curbside-pickup block coordinator program. Volunteer coordinators were recruited through flyers posted in buildings, through connections with the single-family block coordinator program, and through door-to-door contact. The coordinators were 
POPULATION AND ENVIRONMENT

FIGURE 1

Experimental Design and Distribution of Curbcarts

\begin{tabular}{l|c|c|c|c|}
\hline \multicolumn{2}{c|}{ Control } & $\begin{array}{c}\text { Written } \\
\text { Commitment }\end{array}$ & $\begin{array}{c}\text { Postcard } \\
\text { Feedback }\end{array}$ & $\begin{array}{c}\text { Newsletter } \\
\text { Feedback [a] }\end{array}$ \\
\hline $\begin{array}{l}\text { Volunteer } \\
\text { Coordinator }\end{array}$ & $N=15$ & $N=20$ & $N=20$ & $N=20 / 19$ \\
\hline $\begin{array}{l}\text { No Volunteer } \\
\text { Coordinator }\end{array}$ & $N=21$ & $N=16$ & $N=22$ & $N=23 / 18$ \\
\hline
\end{tabular}

[a] Sample sizes are shown as newspaper curbcarts/container curbcarts.

asked to pass out information to residents and display a poster promoting recycling somewhere in their building. Volunteer coordinators contacted residents to administer the written commitment (pledge); those without volunteer coordinators were contacted by the researchers. The written commitment, in this study, was administered by face-to-face contact in which individuals were asked to sign the following statement: "As part of the City of Ann Arbor's Opportunity to Recycle, I and my household will participate in the weekly recycling curbcart collection for at least the next two months. We will recycle glass bottles and jars, tin and aluminum cans, plastic milk jugs, plastic (resin code number 2) detergent bottles, and newspaper; preparing these items according to the directions that the City has provided." If they were unsure about making a commitment, the card was left with them to sign later, if they so desired. If two attempts failed to find residents at home, the pledge was left on the doorknob.

Postcards were used to provide specific feedback to multi-family complexes. The postcards provided cumulative, biweekly averages of the amount of material recycled in the resident's complex. This feedback was both written out and displayed graphically. Information concerning specific contamination problems found in each complex's curbcarts was also included. If no contamination problems had been found, an encouraging comment was written on the postcard.

Newsletters were used to provide general feedback to multi-family complexes. Cumulative, biweekly averages (written and displayed graphically) of the amount of material recycled in the entire multi-family dwelling program were prominently featured in this one page newsletter, entitled the Three Minute Recycler. Feedback on contamination appeared as a 
RAYMOND DEYOUNG ET AL.

separate section highlighting the previous period's most frequently occurring contamination problems. Each newsletter also included a simple fact about waste generation in the United States and a short section dealing with some aspect of recycling of specific interest to multi-family dwellers.

\section{Measurement Procedure}

Although the focus of this study was the recycling behavior of individuals, the unit of analysis was the curbcarts, the only available means of measuring the actual amount of materials recycled. A total of 98 multifamily complexes were included in the study with 157 newspaper curbcarts and 151 container curbcarts assigned to the eight cells. Complexes varied greatly in size and were divided into four size categories as follows: Small (10 or fewer units), medium (11-30 units), large (31-99 units), and very large (100 or more units).

Four dependent measures were used: weight of newspapers and containers (pounds/per unitper week), and the contamination level for containers and newspapers. Recycling behavior of residents was quanitified by measuring the volume of material recycled. Volume readings were then converted to pounds for ease of comparison with other studies. The conversion assumed that a 105 gallon curbcart equaled 0.52 cubic yards, that there are 220 pounds of containers per cubic yard and that there are 500 pounds of newspapers per cubic yard (Apotheker, 1991). The final unit of measure, pounds per unit per week, was calculated by dividing the calculated weight of the curbcart each week by the total number of multi-family units using that curbcart. The method of measuring the volume was pretested and the recycling collection truck drivers were then trained to ensure a consistent measurement technique.

To facilitate the separation of commingled recyclables after collection, drivers routinely removed as much contamination from curbcarts as possible before loading material into the collection trucks. The drivers were asked to rate the level of contamination found in each curbcart by estimating the amount of time it took them to remove the contamination and by assigning ordinal values to the level of contamination on a scale of $0-4$ (with 0 designating no contamination). Drivers were also asked to record the types of contamination found in curbcarts. This information concerning the types of contamination was directly used to create specific feedback (postcards) and indirectly used for general feedback (newsletters). The type of contamination was not factored into any measurement variables nor was it separately analyzed. 


\section{RESULTS}

A two-way analysis of variance with the effects of the treatments (i.e., control, pledge, postcard, newsletter) and volunteer coordinator intervention, controlled by the number of units in each multi-family complex, showed that only the covariant (i.e., number of units) proved to be a significant predictor of the measurement variables newspaper weight $(F=45.49$; $d f=1,148 ; p<.001)$, newspaper contamination $(F=17.18 ; d f=1,148$; $p<.001)$, and container weight $(F=24.70 ; d f=1,142 ; p<.001)$. However, for the container contamination variable, the three treatments $(F=3.14$; $\mathrm{df}=3,142 ; \mathrm{p}<.03)$ and the interaction between these treatments and volunteer coordinators $(F=2.72 ; \mathrm{df}=3,142 ; p<.05)$ proved significant predictors in addition to the number of units $(F=10.87 ; \mathrm{df}=1,142 ; \mathrm{p}=.001)$. This and further analysis that examined subsets of cells in the design (see Figure 1) suggests that volunteer coordinators were ineffective at increasing the quantity or quality of multi-family recycling. Therefore, the volunteer coordinator intervention was not considered in further analysis of these data.

The next stage in the analysis explored the effect of complex size (i.e., number of units) and the four treatments (i.e., control, pledge, postcard, newsletter). Tables 1 through 4 show the mean scores for pounds per unit per week and mean contamination levels of containers and newspapers grouped by complex size and the four treatments. In general, smaller complexes generate a greater weight of recyclables per unit with less overall contamination. Two-way analysis of variance shows that complex size was a significant predictor for newspaper weight, $(F=24.02 ; \mathrm{df}=3,141$; $\mathrm{p}<.001$; Table 1) and newspaper contamination $(\mathrm{F}=2.51 ; \mathrm{df}=3,141$; $p<.07$; Table 2). Complex size also predicted container weight $(F=17.36$;

\section{TABLE 1}

Mean Newspaper Weight (Pounds Per Unit Per Week) Grouped by Treatment and Complex Size

\begin{tabular}{lrrrrrrrrr}
\hline & \multicolumn{8}{c}{ Treatment } \\
\cline { 2 - 10 } & \multicolumn{2}{c}{ Control } & \multicolumn{2}{c}{ Pledge } & \multicolumn{2}{c}{ Postcard } & \multicolumn{2}{c}{ Newsletter } \\
\cline { 2 - 10 } Size & Mean & SD & Mean & SD & Mean & SD & Mean & SD \\
\hline Small & 12.5 & 3.4 & 18.2 & 12.9 & 16.0 & 5.8 & 15.2 & 5.8 \\
Medium & 8.1 & 1.0 & 8.6 & 2.3 & 11.1 & 2.5 & 12.3 & 4.2 \\
Large & 6.9 & 2.8 & 4.6 & 2.3 & 7.2 & 1.0 & 8.7 & 0.3 \\
Very Large & 7.0 & 1.4 & 6.8 & 1.2 & 5.1 & 2.4 & 5.3 & 1.7 \\
\hline
\end{tabular}


TABLE 2

Mean Newspaper Contamination Levels Grouped by Treatment and Complex Size

\begin{tabular}{llllllllll}
\hline & \multicolumn{9}{c}{ Treatment } \\
\cline { 2 - 10 } & \multicolumn{2}{c}{ Control } & \multicolumn{2}{c}{ Pledge } & \multicolumn{2}{c}{ Postcard } & \multicolumn{2}{c}{ Newsletter } \\
\cline { 2 - 10 } Size & Mean & SD & Mean & SD & Mean & SD & Mean & SD \\
\hline Small & 0.18 & 0.19 & 0.21 & 0.23 & 0.09 & 0.09 & 0.24 & 0.28 \\
Medium & $\mathbf{0 . 2 3}$ & 0.15 & 0.31 & 0.25 & 0.18 & 0.06 & 0.25 & 0.25 \\
Large & $\mathbf{0 . 4 4}$ & 0.38 & 0.17 & 0.20 & 0.27 & 0.10 & 0.21 & 0.02 \\
Very Large & $\mathbf{0 . 4 3}$ & 0.35 & 0.29 & 0.26 & 0.64 & 0.80 & 0.56 & 0.83 \\
\hline
\end{tabular}

\section{TABLE 3}

Mean Container Weight (Pounds Per Unit Per Week) Grouped by Treatment and Complex Size

\begin{tabular}{lccccccccc}
\hline & \multicolumn{8}{c}{ Treatment } \\
\cline { 2 - 10 } & \multicolumn{2}{c}{ Control } & \multicolumn{2}{c}{ Pledge } & \multicolumn{2}{c}{ Postcard } & \multicolumn{2}{c}{ Newsletter } \\
\cline { 2 - 10 } Size & Mean & SD & Mean & SD & Mean & SD & Mean & SD \\
\hline Small & 4.1 & 1.9 & 5.5 & 4.0 & 4.6 & 0.7 & 6.0 & 5.2 \\
Medium & 2.7 & 0.1 & 2.7 & 0.9 & 2.7 & 0.6 & 3.4 & 1.5 \\
Large & 2.3 & 0.7 & 1.2 & 0.5 & 2.4 & 0.7 & 3.0 & 0.1 \\
Very Large & 1.8 & 0.4 & 2.1 & 0.8 & 1.6 & 0.7 & 1.9 & 0.4 \\
\hline
\end{tabular}

TABLE 4

Mean Container Contamination Levels Grouped by Treatment and Complex Size

\begin{tabular}{lccccccccc}
\hline & \multicolumn{9}{c}{ Treatment } \\
\cline { 2 - 9 } & \multicolumn{2}{c}{ Control } & \multicolumn{2}{c}{ Pledge } & \multicolumn{2}{c}{ Postcard } & \multicolumn{2}{c}{ Newsletter } \\
\cline { 2 - 9 } Size & Mean & SD & Mean & SD & Mean & SD & Mean & SD \\
\hline Small & 0.73 & 0.52 & 0.59 & 0.46 & 0.50 & 0.15 & 0.91 & 0.88 \\
Medium & 1.21 & 0.18 & 0.85 & 0.56 & 0.47 & 0.18 & 0.74 & 0.36 \\
Large & 1.57 & 0.62 & 0.84 & 0.28 & 0.92 & 0.32 & 0.58 & 0.03 \\
Very Large & 0.96 & 0.48 & 1.09 & 0.42 & 1.20 & 0.73 & 1.01 & 0.50 \\
\hline
\end{tabular}


$\mathrm{df}=3,135 ; \mathrm{p}<.001 ;$ Table 3$)$ and container contamination $(\mathrm{F}=3.19$; $d f=3,135 ; p<.05 ;$ Table 4). Although the treatments were not significant predictors for any of the measurement variables, the interactive effect between complex size and treatment barely reached significance for container contamination $(F=1.80 ; d f=9,135 ; p<.08$; Table 4$)$.

Since taken alone, the individual treatments did not prove to be significant predictors of recycling behavior, they were combined and further analysis explored the effect of using any of the treatments versus the control. Two-way analysis of variance was conducted using complex size and this combination of treatments as the predictors. Only complex size proved to be a significant predictor of the quantity of material recycled $(F=16.29$; $\mathrm{df}=3,149 ; \mathrm{p}<.001$ for the weight of newspaper and $\mathrm{F}=13.01 ; \mathrm{df}=3$, $143 ; p<.001$ for weight of containers). Neither variable was a significant predictor of newspaper contamination. It is worth noting that newspaper contamination was scored extremely low by the drivers doing the evaluation. These scores ranged from a low of 0.18 to a high of .57 out of 4.0 points with the larger scores occurring in the larger complexes.

Only in the case of the mean level of container contamination were both variables significant predictors. Furthermore, the interaction between the combined treatment and complex size also proved significant, suggesting these two predictors operate in a non-additive way. These data are shown in Table 5 along with the results of a series of Tukey HSD compari-

\section{TABLE 5}

Container Contamination Means Grouped by Combined Treatment and Complex Size

\begin{tabular}{lllll}
\hline & \multicolumn{2}{c}{ Control } & \multicolumn{2}{c}{ Combined Treatment } \\
Size & Mean & SD & Mean & SD \\
\hline Small & $0.73 \mathrm{a}^{*}$ & 0.52 & $0.67 \mathrm{~b}, \mathrm{e}$ & 0.59 \\
Medium & 1.21 & 0.18 & $0.74 \mathrm{c}$ & 0.46 \\
Large & $1.57 \mathrm{a}, \mathrm{b}, \mathrm{c}, \mathrm{d}$ & 0.62 & $0.84 \mathrm{~d}$ & 0.29 \\
Very Large & 0.96 & 0.48 & $1.12 \mathrm{e}$ & 0.62
\end{tabular}

Two-way ANOVA Results:

Complex Size Combined Treatment Interaction

\begin{tabular}{lll}
$\mathrm{F}=$ & $\mathrm{df}=$ & $\mathrm{p}<$ \\
\hline 3.76 & 3,143 & 0.02 \\
4.10 & 1,143 & 0.05 \\
3.62 & 3,143 & 0.03 \\
\hline
\end{tabular}

*Means sharing the same subscript are significantly different at $p<: a, c, d, e=.05 ; b=.001$. 
RAYMOND DEYOUNG ET AL.

son tests (Wilkinson, 1990) conducted to explore the interaction effect. These tests show that small complexes in either the combined treatment or control group, achieved significantly lower contamination scores than large complexes in the control group. Small, medium and large complexes receiving any treatment also performed significantly better than large com plexes in the control group. And small complexes receiving any treatment performed better than very large complexes receiving any treatment. No one simple conclusion is suggested in these data. However, taken together, they suggest that smaller complexes contaminate less than larger complexes and that interventions may be most effective in middle sized multi-family complexes.

\section{DISCUSSION}

The data show that size of the multi-family complex is an important predictor of recycling behavior in multi-family dwellings. The smaller the complex, the greater the weight of both newspaper and containers recycled. Smaller complexes also had significantly lower contamination scores for containers. However, newspaper contamination was not significantly affected. This may be explained by reflecting on the nature of the materials being recycled. The container waste stream includes many materials each requiring different types of preparation to avoid contamination (e.g., labels removed from cans but not from glass or plastic, cans and plastic crushed but glass to remain intact, only certain resin plastics accepted). The involved nature of the rules may have increased container contamination. In contrast, only newspapers (with their glossy inserts) and crushed cardboard boxes are accepted in the newspaper curbcarts; no other paper material of any sort is acceptable. These extremely simple rules and the lack of significant preparation makes newspaper recycling a simple task, one difficult to contaminate.

In general, the three treatments (i.e., written commitment, specific feedback, general feedback) were effective only with regard to container contamination and only then when complex size was taken into consideration. At no time did any particular treatment out-perform the others. An overall statement about the effectiveness of the treatments on recycling behavior is as follows: 1) container contamination can be reduced by any of the three treatments in middle sized complexes, 2) none of the treatments improved recycling behavior in the very large complexes, and 3) small complexes will recycle greater amounts with less contamination regardless of whether they receive a treatment. Recycling programs may choose to allocate their resources toward informing and motivating resi- 
dents in medium and large complexes, and avoid using these treatments in the small and very large complexes.

The volunteer coordinator strategy, which has been considered effective in single family programs, did not significantly improve recycling behavior in this study of multi-family dwellings. Neither the amounts recycled nor the level of contamination were affected by the presence of the volunteer coordinators. These findings suggest that volunteer coordinators not be used in multi-family dwelling recycling programs. However, this issue clearly deserves additional research due to the extraordinary success attributed to volunteer coordinators and block leaders in single family programs. It is possible that there are differences in the way volunteer coordinator programs must, of necessity, be implemented in multi-family and single family programs, although in this study there were essentially no differences in the demands made on the volunteer coordinators from those made on volunteer coordinators in the single family program. There is a good economic reason for proceeding with this research at once. The Ann Arbor City Solid Waste Department estimates the annual cost of expanding the use of volunteer coordinators to the multi-family program, considering expenses relating to the high turnover rate of both volunteer coordinators and residents as well as other administrative burdens unique to the multifamily dwelling program, to be $\$ 40,000$ to $\$ 50,000$.

A factor which may have contributed to the ineffectiveness of the volunteer coordinator strategy as well as of the treatments is the already relatively high rates of recycling in Ann Arbor's multi-family dwellings. A pre-test survey of the study participants revealed that 61 percent of the respondents had previously participated in recycling. In regards to total amounts recycled, the weekly averages per dwelling unit for this study were 9.15 pounds of newspapers and 2.79 pounds of containers. Other programs have reported a weekly average per unit of between 3.3 and 9.5 pounds of newspapers and between 1.0 pounds and 4.4 pounds of containers (Hyde, 1990; Zarillo, 1990). Given that multi-family dwellers in Ann Arbor have already been recycling at a high rate, there may be little room for any increase to result from our interventions. Nonetheless, the size of the complex was a significant predictor of the quality and quantity of the materials recycled.

\section{Research Implications of the Scale Effect}

The notion that the scale of multi-family dwellings affects conservation behavior of the residents deserves more research attention. There are several themes worth exploring. Prior work in environmental psychology indi- 
RAYMOND DEYOUNG ET AL.

cates that information processing may be easier in a small scale environment because coherence and predictability are enhanced; thus making it a more preferred environment (Kaplan \& Kaplan, 1982). Because humans function better in a preferred environment, such an environment may lead to a more rapid, reliable and durable change in conservation behavior. An issue here may be that territoriality or sense of ownership is more easily allowed for in small scale settings.

From a social psychology perspective, one might speculate that feelings of anonymity and non-involvement pervade larger complexes. The increased number of social interactions in larger structures may lead to social overload and reduce one's engagement in community-based conservation behavior. The social conditions pervasive in large complexes may serve to erode social norms which control behavior in public places. In particular, the lack of a "sense of community" may adversely affect the recycling behavior of residents in large complexes.

It is also possible that the attitude of owners and managers toward recycling may affect multi-family complex's recycling participation. Reports from St. Paul, Minnesota and Prince George's County, Maryland indicate that the involvement and support of managers may be important to the success of multi-family programs ( $T^{\prime}$ Kach \& Schoenecker, 1990; Hyder, 1990). A survey conducted by the City of Ann Arbor Department of Solid Waste (1989) showed that approximately $45 \%$ of the owners and managers of small, medium and large multi-family complexes were very supportive of recycling, while only $28 \%$ of managers of very large complexes $(250+$ units) reported that they were very supportive of recycling.

In conclusion, as recycling behavior moves beyond its origin in the single family setting into multi-family, institutional, retail and industrial settings, the behavior change techniques may themselves need to change. This research suggests that even the most successful technique in one setting should not be presumed to work, unmodified, in all other settings. Nothing can replace behavior- and setting-specific research.

\section{ACKNOWLEDGMENTS}

We would like to acknowledge support from the University of Michigan School of Natural Resources and Environment and the City of Ann Arbor Department of Solid Waste. This study is part of a larger investigation completed by the APT Master's Project (Project No. 650-33). A report on this larger investigation, entitled "Multi-family Recycling: A Study on Increasing Participation and Decreasing Contamination" may be obtained 
POPULATION AND ENVIRONMENT

by writing the first author at the School of Natural Resources and Environment, University of Michigan, 430 East University Avenue, Ann Arbor, MI 48109-1115.

\section{REFERENCES}

Apotheker, S. (1991). Volume to weight functions: Recycling's manifest destiny. Resource Recycling, 10(11), 69-74.

Barker, R.C. \& Gump, P.V. (1964). Big school, small school. Stanford: Stanford University Press.

Benton C.H., \& Fox, R. (1990). Commingled recycling tested in apartments. Resource Recycling, $9(6), 48-50$.

Burn, S.M. (1991). Social psychology and the stimulation of recycling behavior: The block leader approach. Journal of Applied Social Psychology, 21(8), 611-629.

Burn, S. M. \& Oskamp, S. (1986). Increasing community recycling with persuasive communication and public commitment. Journal of Applied Social Psychology, 16(1), 29-41.

City of Ann Arbor Department of Solid Waste. (1989, September). Multi-farmily housing solid waste survey final report. Ann Arbor, MI.

Cook, S.W. \& Berrenberg, J.L. (1981). Approaches to encouraging conservation behavior: A review and conceptual framework. Journal of Social Issues, 37(2), 73-107.

Davis, G.E. (1978). Designing for residential density. In A. Baum and Y.M. Epstein (Eds.). Human response to crowding. Hillsdale, Nj: Erlbaum, Associates.

Denman, C.C. (1970). Small towns are the future of America. Congressional Record, March 16. E2025, E2026.

De Young, R. (1993). Changing behavior and making it stick: The conceptualization and management of conservation behavior. Environment and Behavior, 25(4), 485-505.

Freedman, 1. (1975). Crowding and behavior. San Francisco: W.H. Freeman and Co.

Geller, E.S. (1989). Promoting safety belt use on a university campus: An integration of commitment and incentive strategies. Journal of Applied Social Psychology, 19, 3-19.

Hopper, J.H. \& Nielsen, J.M. (1991). Recycling as altruistic behavior: Normative and behavioral strategies to expand participation in a community recycling program. Environment and Behavior, 23(2), 195-220.

Hyde, 1. (1990). An experimental apartment recycling program. Resource Recycling, 9(6), 30-32.

Kaplan, S. \& Kaplan R. (Eds.). (1982). Humanscape: Environments for people. Ann Arbor, MI: Uirich's Books, Inc.

Katzev, R.D. \& Pardini, A. (1987-1988). The comparative effectiveness of reward and commitment approaches in motivating community recycling. Journal of Environmental Systems, 17, 93-113.

Magnuson, A. (1990). Apartment recycling. Garbage, 2(6), 32-35.

Pardini, A. \& Katzev, R.D. (1983-1984). The effect of commitment on newspaper recycling. Journal of Environmental Systems, 13, 245-254.

Sadalla, E.K. (1978). Population size, structural differentiation, and human behavior. Environment and Behavior, 10(2), 271-291.

Seligman, C., Becker, L.J. \& Darley, J.M. (1981). Encouraging residential energy conservation through feedback. In A. Baum and J.E. Singer (Eds.). Advances in environmental psychology, Vol. III: (Energy conservation: Psychological perspectives). Hillsdale, NJ: Erlbaum, Associates.

Sherrod, D.R. \& Cohen, S. (1976). Density, personal control, and design. in J.R. Aiello (Ed.). Residential crowding and design. New York: Plenum. 
RAYMOND DEYOUNG ET AL.

T'Kach, M. \& Schoenecker, P. (1990). Practical approaches to multifamily recycling: High rises to house boats. Biocycle, 31(10), 52-54.

U.S. EPA (1990). Characterization of municipal solid waste in the United States: 1990 update. Office of Solid Waste. Washington, DC: U.S. EPA.

Wang, T.H. \& Katzev, R.D. (1990). Group commitment and resource conservation: Two field experiments on promoting recycling. Journal of Applied Social Psychology, 20(4), 265275.

Wilkinson, L. (1990). Systat: The system for statistics. Evanston, IL: Systat, Inc.

Wood, J.J. (1991). The challenge of multi-family recycling. Resource Recycling, 10(6), 34-40.

Zarillo, K. (1990). Multi-family residential recycling: Testing collection systems. Resource Recycling, 9(9), 66-68.

Zimbardo, P.G. (1969). The human choice: Individuation, reason and order versus deindividuation, impulse, and chaos. Nebraska Symposium of Motivation, 17, 237-307.

Zimbardo, P. \& Ebbesen, E. (1969). Influencing attitudes and changing behaviors. Reading, MA: Addison-Wesley. 